\title{
LA LEY NATURAL Y LA PERSONA HUMANA COMO PRINCIPIO Y FUNDAMENTO DEL DERECHO Y DE LOS DERECHOS ${ }^{1}$
}

\author{
Daniel Alejandro Herrera ${ }^{2}$
}

\section{RESUMEN}

Son abordados los temas: "los Derechos Fundamentales"; "Principio y Fundamento de los Derechos”; y “el Fundamento de la Ley Natural y de la Persona Humana”.

Descriptores: Ciencias naturales. Filosofía del derecho. Derechos humanos.

\section{RESUMO}

São abordados os temas: "os Direitos Fundamentais”; "Princípio e Fundamento dos Direitos"; y “o Fundamento da Lei Natural e da Pessoa Humana”.

Descritores: Ciências naturais. Filosofia do direito. Direitos humanos.

\section{PLANTEO DE LA CUESTIÓN}

A 60 años de la declaración Universal de las Naciones Unidas (sobre la que ejerció gran influencia el pensamiento de Jacques Maritain) con la que comienza el proceso de internacionalización de los derechos humanos, es

1 Fuentes: http://www.uca.edu.ar/esp/sec-fderecho/subs-leynatural/esp/docs-articulos/ pdf/herrera-06.pdf y http://www.uca.edu.ar/esp/sec-fderecho/subs-leynatural/esp/docsarticulos/pdf/herrera-principio-fundamento.pdf.

2 Secretario Académico y Profesor Pro-titular de Filosofía del Derecho y Derecho Civil en la Facultad de Derecho de la Universidad Católica Argentina (UCA). Doctorando del Doctorado en Ciencias Jurídicas de la Facultad de Derecho de la UCA. Abogado. Dirección: Av. Pueyrredón $17803^{\circ}$ "A" Capital Federal (1119), Argentina. E-mail: daniel_herrera@uca.edu.ar. 
oportuno plantearse el problema de la fundamentación o justificación racional de los mismos. En otras palabras, si las declaraciones tienen justamente carácter declarativo de derechos preexistentes que se fundan en la misma condición humana o por el contrario son constitutivas al crear derechos anteriormente inexistentes y que por tanto son constituidos positivamente por los instrumentos normativos (nacionales o internacionales) que los crea.

Para algunos como Norberto Bobbio (1965), a esta altura de los acontecimientos no sería necesario buscar un fundamento más allá de las declaraciones de derechos humanos existentes en la actualidad, ni buscar la razón de las razones como pretenden muchos iusnaturalistas. En realidad, esta postura no es neutral, ni simplemente se abstiene de plantear la cuestión de la fundamentación de los derechos, sino que es técnicamente una posición positivista al establecer su justificación por la exclusiva referencia a los instrumentos normativo-positivos constitutivos de los mismos.

Justamente la cuestión del principio y fundamento de los derechos fue siempre el talón de Aquiles del positivismo jurídico, que al identificar el derecho con las normas positivas y al negar la existencia de algún principio, norma o realidad suprapositiva en las que estas se apoyan y justifican racionalmente su existencia y obligatoriedad (pues sería admitir un fundamento metafísico de la realidad jurídica, incompatible con el prejuicio reduccionista propio del modo de conocer positivista), necesariamente tendrían que fundarse a sí mismas, coronando un voluntarismo arbitrario del legislador que se impone por la fuerza no respetando el modo de obligarse y obedecer propio de los hombres que exige una justificación racional (Herrera, 2008).

Paradójicamente esta concepción del derecho cae en una crisis profunda después de la segunda guerra mundial ante la imposibilidad de dar una respuesta a la fundamentación de los derechos humanos frente a las violaciones sistemáticas dentro del marco de ordenamientos jurídicos formalmente válidos y vigentes, lo que por tanto dio origen a la aparición de los instrumentos internacionales que colocan el reconocimiento a los derechos humanos como pilar y punto de partida de la organización política y jurídica de los Estados. En consecuencia, pretender establecer la justificación racional de los derechos en su positivación exclusivamente es entrar en un circulo vicioso, pues en última instancia serían derechos discrecionales, por tanto disponibles y susceptibles de ser derogados por el mismo procedimiento que los creó. En última instancia, sería reemplazar el positivismo nacional que entró en crisis justamente por la cuestión de los derechos humanos, por otro positivismo internacionalista que por tanto adolecería de los mismos de- 
fectos, pues si el consenso internacional cambiara los derechos humanos dejarían de existir.

Como dice Massini Correas,

Ahora bien, esta crisis, pareciera que terminal, del positivismo jurídico de estricta observancia, no ha supuesto que la corriente predominante en la filosofía jurídica actual haya retornado lisa y llanamente al iusnaturalismo clásico; es más, ni siquiera que se considere a si misma como propiamente iusnaturalista. Por el contrario, la gran mayoría de los pensadores antipositivistas se encuentran empeñados en una persistente búsqueda de una nueva vía que, sin recaer en el temido iusnaturalismo, provea al derecho de ciertos elementos racionalmente indispensables: ante todo, de una justificación racional de la obligación jurídica, más allá del mero factum del poder coactivo, sea este estatal o social; y en segundo lugar, de una instancia de apelación ética, desde la cual sea posible juzgar crítica o valorativamente los contenidos del derecho positivo. Pero estos dos elementos son buscados con independencia de cualquier discernimiento de la naturaleza del hombre o de las cosas humanas $y$, en general, de cualquier tipo de conocimiento o de verdad en materias éticas o jurídicas (Massini Corrreas, 1999, p. 20).

Así aparecieron intentos de superación de la oposición iuspositivismoiusnaturalismo, buscando una tercera vía que se diferencie tanto del positi- vismo en crisis, como del iusnaturalismo que consideran superado. Entre estos intentos podemos señalar a las distintas formas de constructivismo ético-jurídico que ante la auto proclamación de la imposibilidad de descubrir estos principios en la realidad (que solo puede ser expresada por juicios descriptivos o de realidad, pero no a través de juicios prescriptivos o normativos propios del conocimiento práctico) buscan construirlos a través de distintos caminos:

- por el contrato que en algunos casos establece los principios de justicia a partir de un consenso imaginario (Rawls);

- por el discurso racional o argumentación a través de la cual por medio de la justificación racional lógica de las argumentaciones se funda el razonamiento práctico, que solo surge de las cualidades formales o procedimentales del discurso (Habermas).

Tampoco "el constructivismo puede dar una respuesta satisfactoria a la cuestión del fundamento del orden ético-jurídico por dos razones que expone claramente el ya citado Massini” (Herrera, 2008, p. 3):

- el consenso es un fundamento débil de carácter relativo y variable que no es apto para fundar una normatividad ético-jurídica fuerte como la de los derechos humanos cuya obligatoriedad es necesaria y exige un respeto incondicionado y sin excepción; 
- el constructivismo procedimental incurre en lo que se puede llamar "la falacia procedimentalista" al pretender obtener principios éticosjurídicos de contenido a través del establecimiento de reglas del procedimiento argumentativo de la razón constructiva, lo que viola la elemental regla de la lógica que sostiene que no podemos arribar a una conclusión (de contenido) que no se encuentre de algún modo en las premisas de las que parto (puramente formales) (Massini Correas, 1999, p. 42 apud Herrera, 2008, p. 3).

En suma, el constructivismo no puede establecer un fundamento objetivo y necesario del obrar humano, pues, si bien es bueno que exista consenso que reconozca ciertos bienes o valores básicos, estos bienes o valores existen y valen, no por el consenso que podamos tener sobre ellos, sino por naturaleza (per se), y los podemos conocer por la ley natural como veremos. Por el contrario, "el consenso solo, sin fundamento alguno no puede constituirse en la base o sostén de todo el orden social, pues no es, ni puede ser por sí mismo, una justificación objetiva común y firme donde se pueda apelar” (Herrera, 2008, p. 1819), sino, que en el mejor de los casos, solo se trata de un punto de referencia intersubjetivo, relativo y variable, que no reúne las condiciones para ser considerado un verdadero fundamento. Además si tenemos en cuenta que solo puede haber consenso entre seres racionales y libres, este consenso supone una previa naturaleza o condición humana que es la de ser racional y libre y por tanto la existencia de una ley anterior por la cual conocemos esa naturaleza que sería la ley natural.

Así pues, la disputa iusfilosofica actual respecto a la cuestión del principio y fundamento del derecho y de los derechos ya no se presenta tanto como iuspositivismo-iusnaturalismo, sino como no cognitivismo ético-jurídico (positivismo residual y algunas formas de constructivismo) frente al cognitivismo ético-jurídico (básicamente iusnaturalista, sin perjuicio de algunos intentos constructivistas) según reconozcan o no la posibilidad o aptitud de la inteligencia de poder descubrir o conocer un orden ético (y jurídico) objetivo y por ende su principio y fundamento.

\section{LOS DERECHOS FUNDAMENTALES}

A su vez el centro de la disputa actual lo constituye la justificación racional o fundamento de los derechos humanos. Antes de comenzar a considerar el tema de la fundamentación, corresponde tratar una cuestión semántica previa, que se refiere al significado que comúnmente se le da a la expresión derechos humanos. En consecuencia, aquí la expresión derechos es utilizada en el sentido de poderes 
o facultades del sujeto respecto de ciertos bienes básicos, mientras que la palabra humanos se referiría a que los sujetos portadores de estos derechos son los seres humanos tomados en tanto tales, o sea, bajo la condición de su hominidad. Esto ya nos plantearía una primera dificultad, pues todos los derechos son en una medida u otra humanos, pues siempre el sujeto de derecho es el hombre, ya sea considerado individual o colectivamente. Por lo tanto, de la expresión derechos humanos se desprendería que se trata de algunos derechos que se distinguen del resto por ser más específicamente humanos que otros, por lo que también se los denomina derechos fundamentales de la persona humana (Massini Correas , 1994, p. 88).

Como dice Antonio E. Perez Luño:

el término 'derechos fundamentales', droits fondamentaux, aparece en Francia hacia el año 1770 en el marco del movimiento político y cultural que condujo a la Declaración del los Derechos del Hombre y del Ciudadano, de 1789. La expresión ha alcanzado luego especial relieve en Alemania, donde bajo la denominación de los Grundrechte se ha articulado, de modo especial tras la Constitución de Weimar de 1919, el sistema de relaciones entre el individuo y el Estado, en cuanto fundamento de todo el orden jurídico-político. Este es su sentido en la actual Grundgesetz de Bonn, la Ley Fundamental de la República
Federal de Alemania promulgada en el año 1949 [...] Durante la segunda mitad del siglo XVIII se produjo la paulatina sustitución del término clásico de los 'derechos naturales' por el de los 'derechos del hombre', denominación definitivamente popularizada en la esfera doctrinal por la obra de Thomas Paine, The Rights of Man (1791-1792). La nueva expresión, al igual que la de los 'derechos fundamentales', forjada también en este período, revela la aspiración del iusnaturalismo iluminista por constitucionalizar, o sea, por convertir en derecho positivo, en preceptos del máximo rango normativo, los derechos naturales (Pérez Luño, 1998, p. 29-32).

Por su parte sobre el mismo tema y a pesar de reconocer la concepción moderna de los derechos fundamentales, sostiene Antonio Truyol y Serra:

Ello no supone evidentemente que el hombre medieval no tenía derechos fundamentales. Lo que ocurre es que la Edad Media, e incluso la Edad Moderna durante el llamado 'Antiguo Régimen' (que en determinadas zonas, movimientos y corrientes se prolongó hasta bien entrado el siglo XIX, en espera de intentar resurgir bajo nuevas formas en el siglo $\mathrm{XX}$ ), conoce 'derechos estamentales', derechos propios de los estamentos, de los 'estados' u 'ordenes' en que aparece estratificada la sociedad feudal [...] Un exponente de tales derechos es la famosa Magna Carta inglesa (1215), documento feudal por su carácter y forma, en el cual Juan sin Tierra 
confirmó a los barones de su reino disposiciones anteriores a su favor y otras que se extenderían también a las demás categorías de súbditos. En realidad, la Edad Media no desconocía que todos los hombres, más allá de su status social y político, participan de un orden ético-natural cuyos principios de base, procedentes del estoicismo antiguo y del cristianismo, son la unidad del género humano, la dignidad de la persona humana, hecha 'a imagen y semejanza de Dios', la igualdad esencial de los hombres. Estos principios permitieron a un sector de la doctrina, especialmente a Santo Tomás de Aquino y su escuela, reconocer a los infieles un derecho natural de dominio privado y público, que les ponía teóricamente a salvo de un supuesto derecho natural de conquista por parte de los cristianos fundado en la infidelidad, que muchos defendían. Aquella fue asimismo la posición de la teología moral española de los siglos XVI y XVII: Vitoria, Las Casas, Soto, Suárez y otros, quienes la desarrollaron sistemáticamente con ocasión del descubrimiento de América y su ocupación por los españoles, con consecuencias de gran alcance para el derecho de gentes y el derecho de colonización (así, las celebres Leyes de Indias) (Truyol y Serra, 1994, p. 12).

Es conveniente considerar como fue la gestación de reconocimientos de estos derechos que fueron receptados por el movimiento constitucionalista primero y posteriormente por el Derecho Internacional Público a través de los tratados y declaraciones interncionales de derechos humanos. Todos estos derechos aparecieron de una manera u otra a modo de reivindicaciones o conquistas frente a los poderes de hecho y de derecho.

Así se dividen los derechos en tres generaciones: 1) Los derechos de primera generación: surgen a partir del primer movimiento constitucionalista posterior a las revoluciones inglesa y francesa y se funda en los derechos absolutos que gozaría el individuo en su estado de naturaleza presocial y prepolítico (Hobbes, Locke, Rousseau y Kant) que fueron reivindicados y conquistados frente al Estado absolutista del régimen anterior, como por ejemplo los derechos individuales fundados en la libertad, que imponen al Estado una abstención. 2) los derechos de segunda generación: de marcado contenido económico social, surgen especialmente a partir de lo que se ha llamado la "cuestión social” como conquistas de los trabajadores frente a un sistema económico ultraliberal e individualista, moderando las consecuencias de la aplicación de un capitalismo salvaje, a través del reconocimiento de los derechos que hacen al trabajo (tanto en cuanto al derecho individual como colectivo) y a la seguridad social. 3) los derechos de tercera generación: también llamados derechos difusos o de incidencia colectiva, donde el titular de los derechos no es la persona singular sino la sociedad en su conjunto, más allá que se reconoz- 
ca a los individuos o a determinadas organizaciones en determinadas condiciones la legitimación para reclamar la plena vigencia de estos por ser un patrimonio común de toda la sociedad, como por ejemplo los derechos que hacen a la preservación del medio ambiente, de los consumidores, etc. (Herrera, 2000, p. 441).

En cuanto a la génesis de los instrumentos jurídico-políticos que los receptan podemos distinguir dos etapas: constitucional e internacional. En la primera etapa, a su vez podemos distinguir una primera parte más individualista y una segunda donde se reconocen los derechos económicos y sociales. En lo que hace a los derechos individuales podemos citar en primer lugar a Inglaterra con tres grandes documentos: 1) La petition of Right (1628) que protege los derechos personales y patrimoniales; 2) El Acta de Habeas Corpus (1679) que hasta hoy tutela la libertad personal en Inglaterra; 3) La Declaration of Rights (1689) sancionada por el parlamento y promulgada por Guillermo de Orange confirmaba los derechos ya consagrados en los textos anteriores. En segundo lugar a los Estados Unidos con dos documentos: 1) Los Bill of Rights (Declaración de Derechos) de Virginia del 12 de junio de 1776; 2) La Declaración de Independencia del 4 de Julio del mismo año que da por supuestos ciertos derechos inalienables. En tercer lugar a Francia con la Declaración de los Derechos del Hombre y del Ciudadano del 26 de agosto de 1789 que encabezó la primera Constitución Francesa de 1791 y de 1793. En cuarto lugar se puede señalar la influencia de esta última declaración en las constituciones de Cádiz de 1812 y de Bélgica en 1831.

Por su parte a partir de mediados del siglo XIX comienza la reivindicación de los derechos económicos y sociales. Así la Constitución francesa de 1848 incorpora algunos derechos relativos al trabajo, la asistencia y la educación. Por su parte bajo la inspiración marxista se encuentra la Declaración rusa de los derechos del pueblo trabajador y explotado del 4 de enero de 1918 y la Constitución Soviética de 1936, como también la Constitución Mejicana de 1917. Por su parte en la Europa occidental podemos citar a la Constitución alemana de Weimar de 1919 que busca la síntesis entre el liberalismo y la democracia social; la Constitución de Irlanda de 1937; las Constituciones francesas de 1946 y 1958; la italiana de 1948; la Ley Fundamental de la República federal de Alemania de 1949; como también las constituciones de Grecia de 1975, de Portugal de 1976 y España de 1978.

En el plano internacional, luego del fracaso de la Sociedad de las Naciones formada después de la primera guerra mundial (de aquella época solo queda la Organización Internacional del Trabajo - OIT - 
creada por el Tratado de Versalles del 28 de junio de 1919 junto con la Sociedad de las Naciones y que hoy es un organismo de las Naciones Unidas), va a ser recién en la Conferencia de San Francisco de 1945, con la aprobación de la Carta de la Organización de las Naciones Unidas donde el proceso de internacionalización de los derechos fundamentales va a adquirir su forma definitiva. Dicho proceso comienza con la Declaración universal de derechos humanos del 10 de diciembre de 1948, que por tratarse de una declaración son solo recomendaciones para que los Estados los incorporen en su ordenamiento jurídico. En 1966 (luego de quince años de negociación en la Comisión de Derechos Humanos) la Asamblea General de las Naciones Unidas aprueba dos Pactos: el Pacto internacional de derechos económicos, sociales y culturales y el Pacto internacional de derechos civiles y políticos que a diferencia de la Declaración de 1948, constituyen verdaderos convenios sujetos a la firma y ratificación de los Estados, con fuerza vinculante para los que los ratifican. A partir de allí comienza en el marco de las Naciones Unidas toda una serie de declaraciones y convenios sobre distintos temas relacionados con los derechos humanos, como ser la discriminación racial, la discriminación contra la mujer, el genocidio, los derechos del niño etc.

Por otra parte también aparece una internacionalización regional por continentes: 1) el 4 de noviembre de 1950 se firmó en Roma la Convención europea para la salvaguardia de los derechos humanos y las libertades fundamentales, que se completó con los protocolos adicionales de París de 1952 y Estrasburgo de 1963. Finalmente en 1961 se firma en Turín la Carta social europea que entró en vigencia el 26 de febrero de 1965 que establece la protección de los derechos económicos, sociales y culturales. 2) la IX Conferencia Internacional Americana, celebrada en la ciudad de Bogotá, Colombia, desde el 30 de marzo hasta el 2 de mayo de 1948 aprobó la Declaración Americana de los Derechos y Deberes del Hombre. Posteriormente, el 22 de noviembre de 1968, en la ciudad de San José de Costa Rica se firmó la convención americana de derechos humanos conocida como Pacto de San José de Costa Rica.

También el Magisterio de la Iglesia, a través del proceso de sistematización de lo que se conoce como "la doctrina social de la Iglesia”, que comienza con la encíclica Rerum Novarum de León XIII (1891) y continua hasta el Magisterio actual de Benedicto XVI, reivindica (a partir de una fundamentación acorde a los principios doctrinales cristianos) la existencia de los derechos fundamentales de la persona humana, tanto individuales como sociales. En efecto, por medio de una serie de documentos magisteriales 
como el ya citado, a los que se agrega Quadragesimo Anno de Pío XI (1931), El Radiomensaje de Navidad de 1942 de Pío XII, Mater et Magistra de Juan XXIII (1961), la Carta Apostólica de S.S. Pablo VI en el $80^{\circ}$ aniversário de la Rerum Novarum (1971); Redemtor hominis (1979), Laborem Excersens (1981) y Centesimus Annus (1991) de Juan Pablo II, junto con la Constitución Pastoral Gaudium et Spes del Concilio Vaticano II, entre otros, han actualizado y aplicado a la realidad actual los principios perennes del cristianismo trasmitidos por la tradición milenaria de la Iglesia.

Entre estos, sobre los derechos fundamentales se destaca la encíclica Pacem in Terris de Juan XXIII (1963) que realiza una profunda fundamentación y enumeración tanto de los derechos como deberes fundamentales. Justamente lejos del individualismo liberal y del colectivismo marxista, Juan XXIII señala que todo ser humano es persona, sujeto de derechos y deberes:

En toda humana convivencia bien organizada y fecunda hay que colocar como fundamento el principio de que todo ser humano es persona, es decir una naturaleza dotada de inteligencia y voluntad libre, y que, por tanto, de esa misma naturaleza directamente nacen al mismo tiempo derechos y deberes que, al ser universales e inviolables, son también absolutamente inalienables (Juan XXIII, 1963, n. 8-9).
En Argentina estos derechos también fueron incluidos en la Constitución en diferentes etapas. Los derechos de primera generación aparecen con la Constitución de 1853/ 60 en su primera parte consistente en la declaración de derechos y garantías; por su parte los derechos de segunda generación aparecen por primera vez en la Constitución de 1949 y luego de su derogación, en la reforma de 1957 que incluye los llamados derechos sociales en el art. 14 bis que incorpora al texto constitucional; mientras que los derechos de tercera generación son incluidos a la Constitución en la última reforma de 1994 al incorporarlos en el capítulo segundo de la primera parte sobre derechos y garantías, bajo el título de "Nuevos derechos y garantías" (en realidad muchos habían sido reconocidos por la jurisprudencia de la Corte como derechos implícitos que surgirían del art. 33 de la Constitución Nacional). Asimismo la reforma de 1994 a través del art. 75 inc. 22 incluye en el texto constitucional las declaraciones y tratados internacionales de derechos humanos que de esta manera adquieren rango constitucional, transformándose nuestro texto constitucional en una Constitución dispersa o difusa, o sea, dividida entre el texto constitucional propiamente dicho y los tratados internacionales con rango constitucional incorporados a la misma (Herrera, 2000, p. 442). 


\section{PRINCIPIO Y FUNDAMENTO DE LOS DERECHOS}

La cuestión puede plantearse en los siguientes términos: ¿existe algún principio, norma o realidad en que se apoya el derecho, los derechos y el orden jurídico? Si existe ¿podemos conocerlo? En otras palabras, el problema que nos ocupa nos pone frente a dos cuestiones: 1) la existencia en el orden del ser de algo que sea su sostén o soporte óntico (principio y fundamento ontológico u óntico); 2) la posibilidad en el orden del conocer de alcanzar una verdad o certeza de la praxis jurídica (principio y fundamento gnoseológico o noético). ${ }^{3}$

Ahora bien, para responder abordaremos finalmente el tema central propuesto: La ley natural y la persona humana como principio y fundamento del derecho y de los derechos. Así nos referiremos a la ley natural como principio y fundamento gnoseológico y a la persona humana como principio y fundamento ontológico.

\subsection{La Ley Natural como Principio y Fundamento Gnoseológico}

En este sentido fundamento se refiere al principio o punto de partida sobre el que se estructura toda una serie de nociones que constituyen una ciencia o conocimiento.

\subsubsection{Intelecto Especulativo e Intelecto Práctico}

Antes de ver los principios de las distintas ciências - donde ubicamos al derecho, la ética y la política)

[...] corresponde considerar la cuestión en el marco de la división del conocimiento en teórico y práctico conforme a la previa distinción del intelecto o razón en teórica o especulativa y práctica y por tanto la consecuente ubicación de las ciencias como teóricas y prácticas. Esta distinción no constituye una separación al modo como la concibió Kant y sus continuadores, sino que conforma una unidad, pues la inteligencia es una única facultad que se ordena a conocer la verdad (teórica) y que por extensión se transforma en práctica al dirigir la acción (verdad práctica) (Aquino, I, 79 sed contra apud Herrera, 2008, p. 9).

Tanto el conocimiento teórico como el práctico se apoyan en primeros principios evidentes (per se nota), indemostrables e inderivados que constituyen su sostén noético.

No obstante en las cosas que caen bajo la aprehensión de los hombres

3 Sobre este punto es ineludible la lectura la lectura de: KALINOWSKI, Georges. El problema de la verdad en la moral y el derecho. Buenos Aires: Editorial Universitaria de Buenos Aires, 1979. 
hallase cierto orden. [...] Así como el ser es lo primero que se aprehende absolutamente [y el primer principio es el de no contradicción, por el cual no se puede afirmar y negar lo mismo, al mismo tiempo y sobre este se fundan todos los demás], así el bien es lo primero que cae bajo la aprehensión de la razón práctica, [...] porque todo agente obra por un fin, que tiene razón de bien.

Y por esto el primer principio en la razón práctica es el no contradicción práctica, que se funda sobre la razón del bien, que es: El bien es lo que todos apetecen (Herrera, 2008, p. 9).

Luego, el primer principio de la ley natural es que el bien debe hacerse y procurarse y evitarse el mal. Y sobre éste se funda todo los demás preceptos de la ley natural, pues todas aquellas cosas a hacer o a evitar que la razón práctica aprehende que son bienes humanos pertenecen la ley natural (Aquino, I-II, 94, 2). Al respecto dice Maritain:

Si la inteligencia humana sabe naturalmente que debe hacerse el bien y evitarse el mal es porque percibe este primer principio como solicitado por el impulso y movimiento de la voluntad hacia la acción, así como para poder obrar conforme a este primer principio la voluntad provoca a la inteligencia a elaborar la ciencia moral (1984, p. 58).

En consecuencia, cada uno de éstos principios es captado [por la inteligencia (nous) o razón (logos)], ya sea teórica o práctica, a partir de un contacto inmediato con la realidad, a través de una abstracción inductiva (Kalinowski, 1979, p. 118; López Martínez, 2006, p. 80),

sin necesidad de ningún discurso o razonamiento a partir de algún principio o premisa anterior. A su vez a cada núcleo de principios (teóricos y prácticos) corresponde un hábito intelectual: el habitus principiorum para los principios teóricos o especulativos y la sindéresis para los principios prácticos (Herrera, 2008, p. 10).

\subsubsection{Los Principios de la Ley Natural}

\section{En este sentido}

los principios prácticos captados por el hábito de la sindéresis como una patencia del bien constituyen el contenido de la ley natural. Dicho de otra manera, son la ley natural. Entre los principios podemos distinguir:

a) los primeros principios (соттиnisima), cuyos términos son captados por todos inmediatamente, por ejemplo, El bien debe hacerse y el mal evitarse como punto de partida de todo el conocimiento de la práxis humana y fundado en este, que según el orden de las inclinaciones será el orden de los principios o preceptos (Aquino, I-II, 94, 2);

b) los secundarios derivados de los primeros, si bien no son inmediatamente conocidos, se obtienen con cierta facilidad, como 
por ejemplo, los preceptos del Decálogo (Aquino, I-II, 100, 11) o la propiedad privada de los bienes (Aquino, II-II, 57, 3);

c) Aquellos sólo accesibles para los más sabios, como es el caso de la prohibición de la usura (Aquino, I-II, 100, 11 apud Herrera, [2008], p. 10).

Como dice García Huidobro: “El criterio para distinguir unos de otros es el grado de dificultad que envuelve su conocimiento" (García Huidobro, 1993, p. 48).

Sin embargo, si bien distinguimos distintos tipos de principios, "diremos que todos esos preceptos de la ley de la naturaleza, en cuanto se refieren a un solo primer precepto tienen razón de una sola ley natural" (Aquino, I-II, Q. 94, art. 2, ad. 1. apud Herrera, 2008, p. 10).

Por su parte, el citado García Huidobro hace una interesante comparación, opinable por cierto, entre los principios de la ley natural que menciona Tomás de Aquino y los bienes humanos básicos como objeto de las inclinaciones a los que se refiere John Finnis en Natural Law, Natural Rights (Finnis, 2000 apud García Huidobro, 1993, p. 97). El propio Finnis hace una comparación parecida y también discutible en su última obra Aquinas. Moral, Political and Legal Theory (Finnis, 2000 apud López Martínez, 2006, p. 116).

Conformealo dichopertenecen ala ley natural, en primer lugar (en común con todos los seres) aquellas cosas por las que se conserva la vida humana y se impide lo contrario (la defensa del bien primario de la vida humana y la condena de todo ataque a la vida inocente, ya sea desde la concepción, como en el caso del aborto, y hasta el final de la vida con la eutanasia); en segundo lugar (en común con los animales) la unión de ambos sexos y la educación de los hijos (cuyo derechodeber corresponde originariamente a los padres y no al Estado que sólo debe actuar subsidiariamente); en tercer lugar (especificamente humano) que el hombre evite la ignorancia, el no dañar a los otros con quien se debe vivir y demás cosas que se refieren a esto. Es por eso un bien esencial o natural al hombre el acceso a la verdad, a conocerla y a exigirla, como también a vivir en sociedad que como tal no es objeto de libre elección, sino una exigencia de su propia naturaleza social o política. Aquí encontramos el fundamento tanto de las libertades básicas (de conciencia, civiles y políticas, etc.) como de los deberes fundamentales para con los demás, ya sea en particular o respecto de la sociedad toda.

Sin perjuicio de ello, como afirma Graneris dejan de ser naturales y resultan antinaturales, las patologías, los vicios, las perversiones etc., en tanto y en cuanto alejan al hombre de su fin perfectivo, que se encuentra inscripto en su propia naturaleza, 
identificándose la naturaleza misma con el fin. En efecto, el hombre libremente en sus opciones concretas a los bienes particulares puede apartarse del orden de la razón y dejarse llevar por un apetito desordenado (lo malo no es el apetito o la pasión que en si mismos son buenos, sino el desorden al subvertirse al orden racional al bien) (AQUINO, 1 ${ }^{\mathrm{a}}, 2^{\mathrm{a}}$, Q. 91 art.6).

\subsubsection{Objeciones a la Ley Natural}

Frente "a esta concepción de la ley natural como principio y fundamento del derecho y de los derechos, podemos señalar tres objeciones principales que se opusieron en parte del pensamiento moderno" (Herrera, 2008, p. 15):

- La ley o principio de Hume por la cual no se puede derivar proposiciones prescriptivas como las que constituyen el contenido de la ley natural, a partir de proposiciones descriptivas como son los juicios de realidad por los que conocemos las realidades naturales (Hume, 2005 apud Herrera, 2008, p. 15); ${ }^{4}$

- La llamada falacia naturalista de Moore, por la cual se niega la posibilidad epistemológica de definir el bien, por considerarla una noción simple que no puedo dividir analíticamente en partes para poder conocerla como sucede con los conceptos complejos (Moore, 1968, p. 9, 37 apud Herrera, 2008, p. 15);
- La falta de consenso sobre su existencia y contenido, pues no todos entienden la ley natural de la misma manera, ni todos admiten por tanto su existencia. Dicho de otra manera, la cuestión es si en una sociedad posmoderna y relativista podemos hablar de ley natural como principio y fundamento de todo orden (Herrera, 2008, p. 15).

[..]

Respecto a la primera objeción, justamente es el pensamiento moderno antimetafísico (que no es todo el pensamiento moderno), empirista $\mathrm{y}$ positivista, el que reduce la noción de naturaleza a las leyes físicas y biológicas constituyendo el eje del problema de la racionalidad moderna conforme lo señalara Benedicto XVI en Ratisbona (Herrera, 2008, p. 15). [...]

En el trasfondo de todo esto subyace la autolimitación moderna de la razón, clásicamente expresada en las «críticas» de Kant, aunque radicalizada ulteriormente entre tanto por el pensamiento de las ciencias naturales. Este concepto moderno de la razón se basa, por decirlo brevemente, en una síntesis entre platonismo (cartesianismo) y empirismo, una síntesis corroborada por el éxito de la técnica. Por una parte, se presupone la estructura matemática de la materia, su racionalidad intrínseca, por decirlo así, que hace posible comprender cómo funciona y puede ser utilizada: este presupuesto de fondo es en cierto modo el elemento platónico en la comprensión moderna de la

4 1, III, cap. I, sec. 1, "in fine”. 
naturaleza. Por otra, se trata de la posibilidad de explotar la naturaleza para nuestros propósitos, en cuyo caso sólo la posibilidad de verificar la verdad o falsedad mediante la experimentación ofrece la certeza decisiva. El peso entre los dos polos puede ser mayor o menor entre ellos, según las circunstancias [...] (Benedicto XVI, 2006 apud Herrrera, 2008, p. 15-16).

[...]

Así, para Hume, lo natural es un mero hecho (factum), conocido empíricamente y que solamente puedo describir mediante juicios de realidad, sin posibilidad de inferir ninguna prescripción para dirigir el obrar moral por constituir una falacia lógica en la que según él cae el pensamiento iusnaturalista. En otras palabras, para esta concepción existe un verdadero abismo entre el orden del ser (reducido a lo fenoménico) y del deber ser, entre determinismo natural y libertad cultural, o entre las ciencias de la naturaleza y las ciencias del espíritu, culturales o sociales (Kselsen, 1977 apud Herrera, 2008, p. 15-16).

En cambio, si superamos el reduccionismo fáctico y recuperamos la plena dimensión del ser que incluye el bien, en la medida en que el ser, en tanto perfectum, es convertible con el bien, que tiene razón de fin y por tanto razón de principio respecto al obrar que se dirige a ese fin, podemos encontrar en el ser el fundamento del deber ser (Pieper, 1974, p. 15). Ampliando lo dicho, el bien moral, que refiere a la bondad del acto humano es un medio o fin intermedio que se funda en el bien ontológico del ser (en este caso humano) que tiene razón de fin último del obrar del hombre, y por el cual es apetecido. En otras palabras, el bien óntico no sería otra cosa que el mismo ser visto bajo la razón de su perfección, o sea, la plenitud del ser y por ende fundamento ontológico de su apeticibilidad. Por tanto la noción de bien en tanto propiedad trascendental del ser es coexistente con la del ser (Derisi Lomanto, 1980, p. 23) y por eso son convertibles: ens et bonun conventutur.

En suma,

todo conocimiento (ya sea teórico o práctico) se funda sobre la noción de ser Porque lo que primeramente cae bajo la aprehensión es el ente y así mientras la inteligencia o razón teórica contempla el ser bajo la razón de verum (verdad); el intelecto o razón práctica lo considera bajo la razón de bonum (bien) (Herrera, 2008, p. 9).

[...]

En verdad, esta concepción reducccionista de la naturaleza acota el conocimiento de la realidad, de la naturaleza, al solo conocimiento de las causas materiales y eficientes, sin consideración de las causas formales y finales que aportan el logos y el sentido a las cosas. Ahora bien, este reduccionismo llevado al extremo es una falacia porque de la afirmación “conozco hechos”, no puedo deducir que sólo conozco o puedo conocer esos hechos y nada más (Herrera, 2008, p. 16). 


\section{[...]}

De esta manera, se demuestra que la concepción clásica de la ley natural y de los primeros principios prácticos evidentes no es alcanzada por la objeción de Hume, porque no son conclusiones obtenidas por medio de un indebido paso de premisas descriptivas (reductivas de la realidad) a conclusiones prescriptivas, sino más bien se trata de proposiciones prescriptivas evidentes paralelas (y no conclusiones deducidas) al orden de las inclinaciones naturales al fin (Kalinowski, 1979 apud Herrera, 2008, p. 16-17), [...] fundadas en una concepción de la realidad no reductiva a lo fáctico, sino ampliada (Benedicto XVI, 2006 apud Herrera, [2008], p. 16-17) a lo ontológico que incluye al bien y al deber ser como manifestaciones del ser en el orden práctico (Herrera, 2008, p. 17).

[...]

En este sentido debe entenderse la conocida tesis de Pieper: "Todo deber ser se funda en el ser. La realidad es el fundamento de lo ético. El bien es lo conforme con la realidad” (Pieper, 1974. p. 15 apud Herrera, 2008, p. 17).

Tampoco es alcanzada por la objeción de Moore, conocida como falacia naturalista, porque no se pretende definir el bien como un concepto analíticamente definible por el género común y la diferencia específica, pues, al tratarse de un trascendental como sucede con el ser con el cual es convertible (ens et bonun conventutur), justamente trasciende todos los géneros y por tanto no es estrictamente objeto de un concepto, sino más bien de un juicio que afirma o niega su existencia y por ende su debitud y exigibilidad (Herrera, 2008, p. 17).

Por último, respecto a la falta de consenso sobre la ley natural y su contenido, corresponde ahora distinguir entre el conocimiento de la ley natural (por el hábito de la sindéresis) y su reconocimiento (por el juicio de la conciencia). Entre el conocimiento evidente de los primeros principios prácticos que obtenemos por la sindéresis y el juicio de la conciencia que se realiza a efectos de aplicarlos a un caso particular aquí y ahora (Ratzinger, 1995 apud Herrera, 2008, p. 17).

Para él,

La principal corriente de la Escolástica expresó los dos planos de la conciencia mediante los conceptos sindéresis y conscientia. La palabra sindéresis (synteresis) procede de la doctrina estoica del microcosmos y es recogida por la tradición medieval de la conciencia. Su significado exacto sigue siendo confuso, y por eso se convirtió en un obstáculo para el desarrollo esmerado de este plano esencial del problema global de la conciencia. Por eso quisiera, sin embarcarme en una disputa sobre la historia de las ideas, sustituir esta palabra problemática por el más claro concepto platónico de anamnesis, que no sólo es linguísticamente más claro y filosóficamente más puro y profundo, sino que, además, está en armonía con motivos esenciales del pensamiento bíblico y con la antropología desarrollada a partir de la Biblia. Con la palabra anamnesis expresamos aquí exactamente lo que dice San Pablo en el segundo capítulo 
de la Epístola a los Romanos: 'En verdad, cuando los gentiles, guiados por la razón natural, sin Ley, cumplen los preceptos de la Ley, ellos mismos, sin tenerla, son para sí mismos Ley. Y con esto muestran que los preceptos de la Ley están escritos en sus corazones, siendo testigo su conciencia' (2,14-15) [...] Eso significa que el primer estrato, que podemos llamar ontológico, del fenómeno de la conciencia consiste en que en nosotros se ha insertado algo así como un recuerdo primordial de lo bueno y de lo verdadero (ambos son idénticos), en que existe una íntima tendencia ontológica del ser creado a imagen de Dios a promover lo conveniente a Dios. Su mismo ser está desde su origen en armonía con unas cosas y en contradicción con otras [...] Después de estas reflexiones sobre el primer plano, esencialmente ontológico, del concepto de conciencia, debemos ocuparnos del segundo estrato, designado en la tradición medieval sencillamente con la palabra conscientia, conciencia. Presumiblemente esta tradición terminológica ha podido contribuir en algo al estrechamiento moderno del concepto de conciencia. Santo Tomás, por ejemplo, solo denomina conciencia a este segundo plano $\mathrm{y}$, en consecuencia, la conciencia no es para él habitus, es decir, una cualidad estable del ser del hombre, sino actus, o sea, un acontecimiento consumado. Sin embargo, Santo Tomás supone evidentemente el fundamento ontológico de la anamnesis (synderesis) como algo dado. El aquinate la define como una resistencia interior contra el mal y una íntima inclinación al bien.
El acto de conciencia aplica este saber fundamental a las situaciones concretas. Según Santo Tomás, consta de tres momentos: reconocer (recognocere, dar testimonio (testificari) y juzgar (iudicare). Se podría hablar de un concierto entre la función de control y la de decisión. Siguiendo la tradición aristotélica, Santo Tomás ve este acontecimiento de acuerdo con el modelo de los procedimientos conclusivos. Sin embargo, subraya enérgicamente lo específico de este saber práctico, cuyas conclusiones no derivan del mero saber ni del puro pensar.

"Reconocer o no reconocer algo depende siempre de la voluntad, que destruye el conocimiento o conduce a él. Depende, pues, del talante moral dado de antemano, el cual se deforma o purifica progresivamente" (Ratzinger, 1995, p. 72 apud Herrera, 2008, p. 18). En este plano, el plano del juicio (conscientia en sentido estricto), es lícito decir que también la conciencia errónea obliga. En la tradición racional de la Escolástica esta proposición es absolutamente clara. Nadie debe obrar contra su conciencia, como ya había dicho San Pablo (Rom. 14, 23). Pero el hecho de que la conciencia alcanzada obligue en el momento de la acción no significa canonizar la subjetividad. Seguir la convicción alcanzada no es culpa nunca. Es necesario, incluso, hacerlo así. Pero sí puede ser culpa adquirir convicciones falsas y acallar la protesta de la anamnesis del ser. La culpa está en otro sitio más profundo: no en el acto presente, ni en el juicio de conciencia actual, sino en el abandono del yo, que me ha embotado para percibir en mi interior la voz de 
la verdad y de sus consejos. De ahí que autores que obraron convencidos, como Hitler o Stalin, sean culpables. Los ejemplos extremos no deberían servir para tranquilizarnos, sino más bien, para sobresaltarnos y hacernos ver con claridad la seriedad del ruego: límpiame de los deslices que se me ocultan (Ps 19, 13) (Ratzinger, 1995 apud Herrera, 2008, p. 17-18).

Este juicio de conciencia, en sentido estricto o propio es individual, pero por una analogía impropia (metafórica) puede extenderse a la sociedad toda y así hablar en sentido lato o impropio de una "conciencia colectiva", que reconoce o niega (falibilidad de la conciencia) las exigencias objetivas de la ley natural como fundamento del orden social y primera regla de la razón práctica por la cual lo conocemos. En consecuencia, cuando en la actualidad muchas veces se afirma que no se puede fundar el orden social moral, político y jurídico en la ley natural, porque no todos la aceptan, ni hay consenso sobre ella, se confunde el problema de la existencia y conocimiento de la ley natural, con su reconocimiento a través del juicio de la conciencia de cada uno de los formadores del consenso. Juicio de conciencia que a veces puede fallar en cuanto a los preceptos secundarios o en la aplicación de los principios a los casos particulares, debido a la influencia de ideologías o intereses contrarios al bien de hombre, a los malos consejos, a la concupiscencia, o bien a costumbres depravadas y hábitos corrompidos (Aquino, 1-2, Q. 94, art. 6.). "Reconocer o no reconocer algo depende siempre de la voluntad, que destruye el conocimiento o conduce a él. Depende, pues, del talante moral dado de antemano, el cual se deforma o purifica progresivamente" (Ratzinger, 1995, p. 72 apud Herrrera, 2008, p. 18).

Justamente el meollo del relativismo es que el debilitamiento de la razón produce un debilitamiento de la conciencia moral, una conciencia más laxa, pues al no tener referencia necesaria a una verdad objetiva pierde su quicio. En efecto, lo que produce el relativismo es la ruptura definitiva entre los dos ámbitos de la conciencia, el objetivo (la ley natural) y el subjetivo (el juicio de la conciencia), desconociendo al primero y coronado como única instancia de apelación moral al segundo, que al no estar anclado en la realidad, corona el más "absoluto" relativismo, valga la paradoja de un relativismo "absoluto".

Por eso, es un grave error (muy común últimamente) hacer depender la existencia y el conocimiento de la ley natural del consenso que exista sobre ella, poniendo de esta manera, el carro delante de los caballos. En realidad, no es la ley natural la que se funda o depende del consenso, sino que es el consenso el que debe fundarse y depender de la ley natural, pues solo puede haber consenso entre seres racionales y libres, que tienen una determinada naturaleza (racional) $\mathrm{y}$ por ende una determinada ley. Desconocer la ley natural porque no hay consenso sobre ella, es confundir sujustificación racional en la evidencia per se nota de sus principios, con la aceptación efectiva de la misma en el juicio de conciencia de todos y cada uno de los hombres, que justamente nos permite distinguir la conciencia recta y verdadera de la conciencia 
errada (vencible o invenciblemente errada) (Herrera, [2008], p. 18-19).

\subsection{La Persona Humana como Principio y Fundamento Ontológico}

En este sentido principio y fundamento se refiere al sostén o soporte óntico de un ente o de una realidad, cualquiera que sea.

\subsubsection{El Derecho como Realidad Accidental}

Toda realidad requiere un soporte óntico: existe en sí (sustancia) o existe en otro (accidente) y a su vez: su existencia la recibe de otro (el ens causado) o no la recibe de ninguno (el esse incausado). En el primer caso, el ser accidental para existir como tal requiere del ser sustancial en el que inhiere, pero a su vez en el segundo caso si este ser sustancial no es el Ser (incausado), tiene o participa del ser porque lo recibe de otro (siendo por tanto un ente causado). En consecuencia, el fundamento último de toda realidad sustancial o accidental es el Ser o esse (incausado) que al participar al ens sustancial (causado) funda al mismo tiempo todos los accidentes que anidan en él (Herrera, 2008, p. 22-23).

\subsubsection{La Persona Humana como Realidad Sustancial}

Sipasamosdelderechocomoaccidente al sujeto que sería la sustancia donde inhiere, esta sería el hombre en tanto constituye una unidad sustancial de cuerpo y alma (corpus et anima unus). Un ser compuesto de cuerpo (materia) y forma (alma), unidos substancialmente, en un único ser substancial donde el cuerpo y el alma no son dos substancias completas, sino más bien dos co-principios sustanciales de un mismo y único ser, que se relacionan como acto (forma) y potencia (materia).

En consecuencia, el alma como forma, es acto primero del cuerpo, única forma substancial en la unidad del compuesto. Por eso a través del alma como forma substancial, el hombre (compuesto de cuerpo y alma) tiene el acto (primero) de ser, que numéricamente es uno y se da en la unidad substancial del compuesto y que en orden de la especie, en tanto forma, lo determina constituyendo junto con la materia informada su esencia. Por eso con la unión substancial del cuerpo y el alma se constituye el hombre en su ser (acto primero) y en su esencia humana (corpórea-anímica o psico-física) que conforma el principio intrínseco de sus operaciones propias (acto segundo), tanto de las específicas de su alma racional, como de las genéricas de su sensibilidad y vegetatibilidad, virtualmente contenidas en su alma racional como única forma substancial del hombre. Y justamente esta esencia como principio intrínseco de operaciones es la naturaleza (Physys), su naturaleza humana. En consecuencia, estas operaciones siguen al ser, pues cada ser opera conforme a su modo de ser o naturaleza (operari sequitur esse), realizando las mismas a través de las distintas potencias del alma y por tanto estas operaciones manifiestan la naturaleza 
y a través de ellas puedo conocerla (Herrera, 2008, p. 23-24).

$$
\text { [...] }
$$

Por eso, en el caso del hombre, de cada hombre, hay un plexo de sujeto y acto de ser. Acto de ser que el hombre que lo recibe por participación de Dios, pero que como acto de ser subsistente (per se) de un ser de naturaleza racional, es [...] necesariamente un acto de ser personal, o sea, constitutivo de la persona, que lo distingue como alguien (sujeto) y no meramente algo (objeto), en el universo (Wojtyla, 1982, p. 90 apud Herrera, 2008, p. 26).

También Robert Spaemann hace la distinción entre "alguien” y "algo":

La persona es alguien, no algo, no un mero caso de una esencia indiferente frente a él [...] las personas son individuos que existen per se y tienen dominiun sui actus, dominio de sus propias acciones. Sus acciones no resultan simplemente de su naturaleza. De ellas se puede decir, más bien: Non solum aguntur, sicut alia, sed per se aguntur. No sólo actúan como las demás cosas, sino que obran por sí mismas. Es decir, son libres (Spaemenn, 2000, p. 48, 50).

En otras palabras, este hombre constituye una sustancia (que existe per se), individual (indistinto en sí mismo, pero distinto de lo demás (Aquino, I, 29, 4), de naturaleza (esencia o ousía como principio operativo en orden al fin), racional (en virtud de su alma espiritual pero unida constitutivamenteconelcuerpo), loque constituiría la tradicional definición de persona de Boecio: Persona proprie dicitur naturae rationalis individua substantia (Boethius, ${ }^{5}$ 1845-1855 apud Wojtyla, 1982, p. 90).

Por eso si partimos de esta definición tradicional de persona, el sujeto de la definición (que refiere al ente que se identifica con la persona) sería la substancia como sustrato primario y fundamental del ser, sujeto de los accidentes, de las potencias, del obrar y del ocurrir. Una sustancia de unas características determinadas (la naturaleza racional) que la distingue de otras substancias (irracionales) (Herrera, 2008, p. 24).

Justamente como dice Maritain:

El sujeto, supósito o persona, posee una esencia, una estructura esencial; es una sustancia dotada de propiedades, y que recibe o padece por medio de sus facultades o potencias. La persona es una sustancia que tiene por forma sustancial un alma espiritual, y que vive una vida no sólo biológica e instintiva, sino intelectual y voluntaria (1982, p. 104).

5 BOETHIUS, Anicius Manlius Torquatus Severinus [480?-524]. De duabus naturis et una persona Christi. Paris: Migne, 1845-1855. cap. 3. (Patrologiae cursus completus, Series 11, Patres Ecclesiae Latinae, 64, col. 1345, n. 1343 d.). 
Como necesariamente,

el alma espiritual creada directamente por Dios es singular, creada en el mismo instante de su unión con el cuerpo individual y concreto que informa, por dicha unión comunica al cuerpo y a todo el hombre el acto singular de ser, único y distinto del acto singular de ser de todo otro hombre. Por eso, el alma espiritual en tanto acto primero del cuerpo es necesariamente incomunicable, pues si así no fuera y pudiera comunicar su mismo ser a otro, ese ser humano dejaría de ser el que es, para convertirse en otro, lo que es palmariamente imposible. En consecuencia, cada ser humano es único e irrepetible y por lo tanto incomunicable en su ser y no intercambiable con ningún otro, lo que lo convierte en un ser ontológicamente cerrado en sí mismo (Herrera, 2008, p. 26-27).

\section{Ahora bien,}

sin perjuicio de la incomunicabilidad radical de su ser, la persona humana, es, sin embargo, bajo otro aspecto, un ser abierto al mundo y al otro, pero en tanto otro, o sea, manteniendo la alteridad. Por lo tanto, así como la incomunicabilidad radical de su ser se funda en la ontología de la persona, la comunicabilidad con el mundo y los demás también se funda en la misma ontología, en tanto constituye una perfección accidental (relacional) de su sustancialidad individual. Esta apertura es intencional en cuanto se realiza a través del conocimiento. El conocimiento intelectual es la actividad (acto segundo) especifica de su naturaleza racional que supone el acto de ser participado en cada sustancia individual o persona (acto primero).

Esta perfección accidental en el orden de la relación (la persona humana no es una relación pero es un ser en relación), no es un mero agregado extrínseco y accesorio a su naturaleza, sino que se trata de un accidente propio que se sigue necesariamente de su misma esencia o naturaleza racional. En otras palabras, se funda en la naturaleza social y política de la persona humana (el zoom polytykon de Aristóteles), por la cual la sociedad como plexo de relaciones es una realidad accidental aunque necesaria (por eso es un accidente propio o mas bien una propiedad) que constituye un todo virtual que inhiere en la persona humana como en su sustancia, que a su vez constituye un todo substancial (Herrera, 2008, p. 27).

Por eso el Aquinate va a definir la persona (distinguiéndola de todo otro supossitum o hipóstasis) por la dignidad de su naturaleza racional: 'la hipóstasis que se distingue por alguna propiedad perteneciente a la dignidad'(Aquino, v. I, cap. 29, 3, 2). En consecuencia, para el Aquinate "Persona significa lo más perfecto que hay en toda la naturaleza, o sea el ser subsistente en la naturaleza racional (scilicet subsistens in rationali natura)” (Aquino, v. I, cap. 29, 3).

Por su parte,

el estatuto ético-jurídico de la persona humana contempla tanto al 
sujeto del obrar moral, como al sujeto jurídico titular de derechos y deberes. Así para la concepción ontológica tenemos que distinguir la acepción filosófica de persona (sustancia individual de naturaleza racional), de su acepción moral (sujeto del obrar moral) y jurídica (sujeto de derecho). En realidad estas nociones no se contraponen, pues la existencia del sujeto de la acción moral, como de los distintos status con sus respectivos derechos y deberes, en el plexo de relaciones jurídicas que existen dentro de la comunidad política, suponen un status básico común que es la condición humana y que coincide con la concepción ontológica de la persona, que por ser más amplia y genérica incluye a la moral y a la jurídica como más especiales y específicas, dado que la moralidad y la juridicidad surgen de la racionalidad y su consecuente sociabilidad que constituyen al suppositum individual en persona humana (Herrera, 2008, p. 31).

\section{Dice Hervada Xiberta:}

En otras palabras, el ser de la persona implica inherentemente, intrínsecamente, el deber ser, Se observa que aquí se entrecruzan dos cosas: la ética y el derecho. Hay un deber ser moral, que se plasma en que el hombre debe vivir según su condición de persona. Y hay un deber ser jurídico de los demás respecto de la persona (1992, p. 46 apud Herrera, 2008, p. 31).

[...]

Por eso, caído el antiguo régimen hoy se reconoce al status básico común del ser humano como fundamento jurídico natural de su ser persona, en tanto sujeto de derecho, titular de derechos y deberes y de su isonomía (igualdad básica ante la ley), más allá de las desigualdades posteriores propias a su condición o ubicación dentro del orden social (Herrera, 2008, p. 33).

Podemos citar nuevamente a Hervada Xiberta:

Todo sistema jurídico positivo se basa, al menos, en la juridicidad natural de los hombres, esto es, en que por naturaleza existe la capacidad y tendencia de relacionarse jurídicamente. La condición de sujeto de derecho - como la condición de sujeto de la comunicación oral - no es cultural sino natural. Y adviértase que no se trata simplemente de que todo hombre puede ser, si se quiere, capaz de derechos. La juridicidad natural significa que, por naturaleza, el hombre está relacionado jurídicamente con los otros y, en consecuencia, que es por naturaleza protagonista del sistema jurídico. Ser persona no es de origen positivo sino natural, porque los hombres, por naturaleza, son sujetos de derecho [...] la condición ontológica de persona incluye la subjetividad jurídica, de modo que el concepto jurídico de persona no puede ser otra cosa que el concepto mismo de persona en sentido ontológico, reducido a los términos de la ciencia jurídica. Dicho en otros términos, el concepto jurídico de persona no es más que aquel concepto que manifiesta lo jurídico de la persona o ser humano 
(Hervada Xiberta, 2001, 119, 122 apud Herrera, [2008], p. 33).

\section{EL FUNDAMENTO DE LA LEY NATURAL Y DE LA PERSONA HUMANA}

Nos queda por último hacer una referencia a su vez al fundamento tanto de la ley natural, como de la persona humana. La crisis del fundamento ha sido justamente la clave de la crisis de la modernidad. Al respecto señala Benedicto XVI (2007 apud Herrera, 2008, p. 35):

Entre estas, quiero mencionar en primer lugar la necesidad de un estudio exhaustivo de la crisis de la modernidad. Durante los últimos siglos, la cultura europea ha estado condicionada fuertemente por la noción de modernidad. Sin embargo, la crisis actual tiene menos que ver con la insistencia de la modernidad en la centralidad del hombre y de sus preocupaciones, que con los problemas planteados por un "humanismo" que pretende construir un regnum hominis separado de su necesario fundamento ontológico. Una falsa dicotomía entre teísmo y humanismo auténtico, llevada al extremo de crear un conflicto irreconciliable entre la ley divina y la libertad humana, ha conducido a una situación en la que la humanidad, por todos sus progresos económicos y técnicos, se siente profundamente amenazada (Benedicto XVI, 2007 apud Herrera, 2008, p. 35).
Por eso, respecto al necesario fundamento ontológico

frente a este proceso moderno y contemporáneo de desconstrucción de la metafísica, habría que oponer una reconstrucción de la misma. Pero pienso que formularlo de esa manera significaría una concesión al pensamiento débil descontructivista, pues parecería reconocer que su prejuicio antimetafísico realmente hizo mella en el pensamiento fuerte del realismo filosófico, lo cual es falso. O sino por el contrario puede parecer que la metafísica sea algo que podamos construir o desconstruir " $a$ piacere". Por eso prefiero hablar de una re-afirmación de la metafísica.

[...]

Si bien existen distintas concepciones que pueden ser legitimas, el sólido pensamiento de Santo Tomás de Aquino, seguido por Maritain tiene una ventaja sobre ellas, pues con la originalidad de su distinción entre esencia y acto de Ser, va más allá de la distinción entre materia y forma que se da en el plano de la esencia y de esta manera nos permite superar tanto al esencialismo formalista (por medio de la primacía del acto de Ser), como al existencialismo radical que no reconoce las esencias (p.ej. Sartre) que está en la base de todo este pensamiento descontructivista y antimetafísico. De la misma manera, con la noción de participación metafísica (que en el siglo XX resaltara Fabro) del ente (que tiene el ser participado) en el Ser imparticipado (ipsum esse subsistem), que se da en el marco 
de una concepción de la creación y de la creaturidad, entendida como relación trascendental y constitutiva de dependencia (en el ser) respecto al Creador, la metafísica tomista como expresión máxima de la razón humana se integra con la Fe que se funda en la revelación divina, en una síntesis magistral e insuperable. El desafío no es simplemente repetirla literalmente sino apoyados en ella repensar la realidad actual con su problemática con el mismo espíritu realista que animó al aquinate (Herrera, 2008, p. 35-36).

Es necesario que por encima exista una concepción fundada en una verdadera antropología y metafísica del hombre, entendido como creatura, unidad substancial de cuerpo y alma, cuerpo animado y alma incorporada. En consecuencia, el fundamento último no sólo del orden social moral, político y jurídico, sino del hombre mismo, de su naturaleza y de su ley natural, es Dios como creador, sin perjuicio que su conocimiento no es evidente como en el caso de los principios de la ley natural, sino analógico a partir de los seres creados. En consecuencia, si bien no es necesario remontarse al acto de Ser de Dios para justificar el razonamiento práctico que se deriva de los primeros principios evidentes de la ley natural, su Ser es el fundamento último de todo lo que existe, del hombre, de su ley y de su obrar (Herrera, 2008, p. 21).

Como dice Finnis,

Pero así como el hecho de que puede darse una buena explicación del movimiento molecular sin aludir a la existencia de un creador increado del completo estado de cosas en que tienen lugar las moléculas y las leyes del movimiento, no implica por sí mismo que no sea necesaria una explicación adicional de ese estado de cosas, o que no esté disponible tal explicación adicional, o que la existencia de un creador increado no sea esa explicación, así el hecho de que la ley natural pueda ser comprendida, aceptada, aplicada y analizada reflexivamente sin aludir a la cuestión de la existencia de Dios, tampoco implica por si mismo que no sea necesaria una explicación adicional del hecho de que existen pautas objetivas sobre el bien y el mal y principios de razonabilidad (sobre lo moralmente correcto e incorrecto), o que no esté disponible tal explicación adicional, o la existencia y naturaleza de Dios no sea esa explicación (Finnis, 2000, p. 81).

\section{En realidad,}

la explicación adicional es en última instancia la explicación fundamental, o sea, la explicación del fundamento del obrar humano, aunque no sea necesario remitirse a ella para justificar racionalmente el razonamiento práctico (justificado por su referencia a los primeros principios evidentes) por el que se dirige dicho obrar (Herrera, 2008, p. 22).

\section{Por otra parte cuando hablamos}

del hombre como sujeto de derechos y deberes, nos estamos refiriendo a la 
persona humana como supositum, o subsistencia individual de naturaleza (ousía, substancia o esencia) racional. Dicho de otra manera, el sujeto del derecho y del orden social, moral, político y jurídico es el hombre, es la persona humana, con su naturaleza y dignidad, que conoce y expresa a través de la ley natural moral, en la que se fundan tanto sus derechos como sus deberes fundamentales (Herrera, 2008, p. 22).

\section{CONCLUSIÓN}

En suma,

el principio y fundamento gnoseológico del derecho y de los derechos y deberes sería la naturaleza misma de las cosas humanas (ex ipsa natura rei) que conocemos por la ley natural como conocimiento evidente constituido por el primer principio que rige el obrar humano: se debe hacer el bien y evitar el mal, y aquellos otros que se siguen inmediatamente a partir de él y que conocemos paralelamente (no deductivamente) a las inclinaciones humanas, a través del hábito intelectual de la sindéresis (hábito de los primeros principios prácticos) (Herrera, 2008, p. 37).

Ley natural que a su vez es completada y concretada por las leyes positivas.

En cambio, el principio $y$ fundamento ontológico de los derechos y deberes sería el hombre como persona humana (ente subsistente en el género, ousía o naturaleza racional), donde estos accidentes inhieren, siendo por tanto el sujeto de los derechos y deberes y portador de una esencial dignidad.

Ahora bien, ambos son aspectos de un único último principio y fundamento: Dios, en quien ser y conocer; persona y ley se identifican. A diferencia que en nosotros en que el orden del ser se distingue del orden del conocer, siendo inversamente proporcionales, pues mientras el orden del ser va de las causas a los efectos, el del conocer va de los efectos a las causas. Por otra parte como el ser o realidad es el objeto y medida de nuestro conocer, el fundamento ontológico funda a su vez el gnoseológico sirviéndole de soporte metafísico. Por eso como decía Aristóteles (1988, v. 1 , sección 2 , cap. 2, 11) nuestro conocimiento va desde lo primero y mas conocido para nosotros (los efectos) hasta lo primero y mas conocido por naturaleza (las causas) (Herrera, 2008, p. 37).

En este sentido para terminar podemos citar el discurso de Benedicto XVI ante las Naciones Unidas:

La referencia a la dignidad humana, que es el fundamento y objetivo de la responsabilidad de proteger, nos lleva al tema sobre el cual hemos sido invitados a centrarnos este año, en el que se cumple el 60 aniversario de la Declaración Universal de los Derechos del Hombre. El documento fue el 
resultado de una convergencia de tradiciones religiosas y culturales, todas ellas motivadas por el deseo común de poner a la persona humana en el corazón de las instituciones, leyes y actuaciones de la sociedad, y de considerar a la persona humana esencial para el mundo de la cultura, de la religión y de la ciencia. Los derechos humanos son presentados cada vez más como el lenguaje común y el sustrato ético de las relaciones internacionales. Al mismo tiempo, la universalidad, la indivisibilidad y la interdependencia de los derechos humanos sirven como garantía para la salvaguardia de la dignidad humana. Sin embargo, es evidente que los derechos reconocidos y enunciados en la Declaración se aplican a cada uno en virtud del origen común de la persona, la cual sigue siendo el punto más alto del designio creador de Dios para el mundo y la historia. Estos derechos se basan en la ley natural inscrita en el corazón del hombre y presente en las diferentes culturas y civilizaciones. Arrancar los derechos humanos de este contexto significaría restringir su ámbito y ceder a una concepción relativista, según la cual el sentido y la interpretación de los derechos podrían variar, negando su universalidad en nombre de los diferentes contextos culturales, políticos, sociales e incluso religiosos. Así pues, no se debe permitir que esta vasta variedad de puntos de vista oscurezca no sólo el hecho de que los derechos son universales, sino que también lo es la persona humana, sujeto de estos derechos (Benedicto XVI, 2008).

\section{REFERENCIAS}

AQUINO, Santo Tomás de [12251274].

ARISTÓTELES [384-322aC]. Analíticos segundos [=Analytica posteriora]. Trad. de M. Candel Sanmartín. Madrid: Gredos, 1988. 2 v.

BENEDICTO XVI. Encuentro con el mundo de la cultura: discurso Santo Padre en la Universidad de Ratisbona [Alemania]: fe, razón y universidad: recuerdos y reflexiones: 12 de septiembre de 2006. [Roma]: Libreria Editrice Vaticana, 2006. Disponible el: $<$ http://www.vatican.va/holy_father/benedict_xvi/speeches/2006/ september/documents/hf_ben-xvi_spe_20060912_university-regensburg_sp.html>. Aceso en: 12 dec. 2008.

BENEDICTO XVI. Encuentro con los miembros de la Asamblea General de las Naciones Unidas: discurso de su Santidad Benedicto XVI, Nueva York, 18 de abril de 2008. [Roma]: Libreria Editrice Vaticana, 2008. Disponible el: $<$ http://www.vatican.va/holy_father/benedict_xvi/speeches/2008/ april/documents/hf_ben-xvi_ spe_20080418_un-visit_sp.html>. Aceso en: 12 dec. 2008. 
BENEDICTO XVI. Discurso del Papa Benedicto XVI a los participantes en el Encuentro Europeo de Profesores Universitarios: 23 de junio de 2007. [Roma]: Libreria Editrice Vaticana, 2007. Disponible el: <http://www.vatican.va/holy_father/benedict_xvi/ speeches/2007/june/documents/ hf_ben-xvi_spe_20070623_european-univ_sp.html>. Aceso en: 12 dec. 2008.

BOBBIO, Norberto [1909-2004]. Sul fondamento dei diritti dell'uomo. Rivista Internazionale di Filosofía del Diritto, Milano, v. 42, abril/ junio 1965, p. 302-309.

DERISI LOMANTO, Octavio Nicolás [1907-2002]. Los fundamentos metafísicos del orden moral. 4. ed. Buenos Aires: EDUCA, 1980.

FINNIS, John. Ley natural y derechos naturales. Buenos Aires: Abeledo Perrot, 2000.

GARCÍA HUIDOBRO, Joaquín. Razón práctica y derecho natural. Valparaíso: Edeval, 1993.

HERRERA, Daniel Alejandro. La ley natural y la persona humana como principio y fundamento del derecho y del orden jurídico. [Buenos Aires]: Pontificia Universidad Católica Argentina, [2008]. 38 f. Disponible el: http://www.uca. edu.ar/esp/sec-fderecho/subsleynatural/esp/docs-articulos/pdf/ herrera-principio-fundamento.pdf. Aceso en: 15 dec. 2008.
HERRERA, Daniel Alejandro. La noción de derecho en Villey y Kalinowski. Buenos Aires: Educa, 2000.

HERVADA XIBERTA, Javier. Intro-ducción crítica al derecho natural. Pamplona: Ediciones Universidad de Navarra, 2001. 200 p. (Manuales de Derecho).

HERVADA XIBERTA, Javier. Lecciones propedéuticas de filosofía del derecho. Pamplona: Ediciones Universidad de Navarra, 1992. 647 p.

HUME, David [1711-1776]. Tratado de la naturaleza humana. 4. ed. Madrid: Tecnos, 2005. 888 p. (Clasicos del Pensamiento). Disponible, una traducción del inglés, por Vicente Viqueira, el: http://www.cervantesvirtual.com/ servlet/SirveObras/01479429800 114973089079/index.htm. Aceso en: 15 dec. 2008.

JUAN XXIII. Pacem in Terris. Roma, 1963. Disponible el: http://www. vatican.va/holy_father/john_ xxiii/encyclicals/documents/hf_jxxiii_enc_11041963_pacem_ sp.html. Aceso en: 12 dec. 2008.

KALINOWSKI, Georges. El problema de la verdad en la moral $y$ en el derecho. Buenos Aires: Editorial Universitaria de Buenos Aires, 1979.

KELSEN, Hans. Teoría pura del derecho. Buenos Aires: Editorial Universitaria de Buenos Aires, 1977. 
LÓPEZ MARTÍNEZ, Adela. MOORE, George Edward. Principia El debate anglo americano ethica. Candbrige: Candbrige, contemporáneo sobre la teoría 1968. tomista de la ley natural. Roma: PÉREZ LUÑO, Antonio Enrique. Los Edizioni Universitá Della Santa derechos fundamentales. Madrid: Croce, 2006. Tecnos, 1998.

MARITAIN, Jacques. Breve tratado acerca de la existencia y de lo existente. Buenos Aires: Club de Lectores, 1982.

MARITAIN, Jacques. Para una filosofía de la persona humana. Buenos Aires: Club de Lectores, 1984.

MASSINI CORREAS, Carlos Ignacio. El derecho natural $y$ sus dimensiones actuales. Buenos Aires: Ábaco de Rodolfo Depalma, 1999.

MASSINI CORREAS, Carlos Ignacio. Filosofía del derecho. Buenos Aires: Abeledo-Perrot, 1994.

PIEPER, Josef. El descubrimiento de la realidad. Madrid: Rialp, 1974.

RATZINGER, Joseph. Verdad, valores, poder. Madrid: Rialp, 1995.

SPAEMENN, Robert. Personas, acerca de la distinción entre algo y alguien. Pamplona: EUNSA, 2000.

TRUYOL Y SERRA, Antonio. Los derechos humanos: declaraciones y convenios internacionales. Madrid: Tecnos, 1994.

WOJTYLA, Karol. Persona y acción. Madrid: BAC, 1982. 